\title{
FGF2 and FGFR2 in patients with idiopathic pulmonary fibrosis and lung cancer
}

\author{
$\mathrm{LI} \mathrm{LI}^{1,2}$, SUFANG ZHANG ${ }^{3}$, LEI WEI ${ }^{1,2}$, ZHONGFU WANG $^{1,2}$, \\ WEI MA ${ }^{1,2}$, FANGYING LIU ${ }^{1,2}$ and YECHANG QIAN ${ }^{1,2}$ \\ ${ }^{1}$ Department of Respiratory Disease, Baoshan Branch, Shuguang Hospital, Shanghai University of \\ Traditional Chinese Medicine; ${ }^{2}$ Department of Respiratory Disease, Baoshan District Hospital of \\ Integrated Traditional Chinese and Western Medicine, Shanghai 201900; ${ }^{3}$ Department of \\ Traditional Chinese and Western Medicine, Shanghai Pulmonary Hospital, \\ Tongji University School of Medicine, Shanghai 200082, P.R. China
}

Received March 11, 2018; Accepted June 1, 2018

DOI: $10.3892 /$ ol.2018.8903

\begin{abstract}
The aim of this study was to investigate the expression of FGF2 and FGFR2 in patients with idiopathic pulmonary fibrosis (IPF) and lung cancer (LC) as well as their clinical significance. Reverse transcription-quantitative PCR (RT-qPCR) and western blotting were used to detect FGF2 and FGFR2 expression in LC and adjacent normal tissues of LC patients and lavage fluid of idiopathic pulmonary fibers patients and normal controls (confirmed by bronchoalveolar lavage examination). The expression levels of FGF2 mRNA and protein in the non-small cell LC tissues were significantly higher than those in the adjacent normal tissues $(\mathrm{P}<0.001)$. The expression level of FGF2 protein in lavage fluid of patients with IPF was higher than that of the control group $(\mathrm{P}<0.001)$. The expression level of FGFR2 mRNA in the non-small cell LC tissues was significantly higher than that in the adjacent normal tissues $(\mathrm{P}<0.001)$. The expression level of FGFR2 protein in the non-small cell LC tissues was higher than that in the adjacent normal lung tissues $(\mathrm{P}<0.001)$. The expression levels of FGF2 mRNA and FGFR2 mRNA in cancer tissues were not significantly correlated with age, sex and history of smoking ( $P>0.05)$, but were significantly correlated with lymph node metastasis, tumor differentiation and TNM staging. FGF2 and FGFR2 proteins were highly expressed in cancer tissues of LC patients and lavage fluid of patients with IPF. The expression of FGF2 mRNA and FGFR2 mRNA was correlated with lymph node metastasis and TNM stage. The high expression levels of $F G F 2$ mRNA and FGFR2 mRNA were associated with tumor metastasis and poor prognosis of LC patients.
\end{abstract}

Correspondence to: Dr Yechang Qian, Department of Respiratory Disease, Baoshan Branch, Shuguang Hospital, Shanghai University of Traditional Chinese Medicine, Shanghai 201900, P.R. China E-mail: qc482k@163.com

Key words: FGF2, FGFR2, idiopathic pulmonary fibrosis, lung cancer

\section{Introduction}

Cancer is one of the most important public health problems faced by human beings all over the world, and lung cancer (LC) is one of the most common cancers with the highest mortality rate among all malignant tumors (1). Approximately 2 million patients in developing countries die each year due to LC, and incidence and mortality of LC showed an increasing trend in recent years, and the onset age is becoming increasingly younger $(2,3)$. LC mainly affects patients between $60-70$ years, and the incidence is higher in men than in women. Surgical treatment is the main treatment for patients with LC, while most patients are diagnosed at advanced stages and chemotherapy and targeted drug therapy for those patients failed to significantly improve the 5-year survival rate, leading to poor prognosis (4). Therefore, early diagnosis and treatment is critical for the survival of patients with LC.

Idiopathic pulmonary fibrosis (IPF) is a characteristic pathological change from common interstitial pneumonia to chronic inflammatory interstitial lung disease. The main manifestations of IPF include pulmonary fibrosis and diffuse alveolitis. Fibrosis of lung tissue leads to increase in hardness of the lung tissue and decrease in compliance $(5,6)$. The median survival time of IPF patients after diagnosis is as short as 2-3 years, and 5-year survival rate is only $20 \%$, seriously influencing the patient's life. Current diagnostic methods for IPF are mainly based on pulmonary imaging examinations and clinical features, but these methods do not provide information for the prognosis of those patients during treatment (7).

In recent years, studies have shown that FGFs and FGFRs form the FGFR pathway. Studies have shown that the FGFR pathway participates in the body's growth and development, wound healing, tumor formation, fibrosis and inflammatory reactions (8). Therefore, we detected the expression of FGF2 and FGFR2 in LC and IPF. Our findings provide new insights into the diagnosis and treatment of LC and IPF.

\section{Patients and methods}

Clinical data. In this study, 108 patients with LC who were treated in Shanghai Pulmonary Hospital (Shanghai, China) 
Table I. Primer sequences.

\begin{tabular}{lll}
\hline Genes & \multicolumn{1}{c}{ Forward } & \multicolumn{1}{c}{ Reverse } \\
\hline$F G F 2$ & 5'-CGGCTGTACTGCAAAAACGG-3' & 5'-GATGTGAGGGTCGCTCTTCTCC-3' \\
$F G F R 2$ & 5'-TACCAAATCTCCCAACCAGAAG-3' & 5'-CCCATCCTTAGTCCAACTGAT-3' \\
GAPDH & 5'-CAGGGCTGCTTTTAACTCTGGTAA-3' & 5'-GGGTGGAATCATATTGGAACATGT-3' \\
\hline
\end{tabular}

from May 2013 to July 2016 were collected. Cancerous tissues and adjacent healthy tissues were collected during surgery. Tissues were stored in liquid nitrogen. In addition, 88 cases of IPF patients and 100 normal people with cough were also collected in Shanghai Pulmonary Hospital. Lavage fluid was collected from IPF patients and normal controls.This study was approved by the Medical Ethics Committee of Shanghai Pulmonary Hospital (Shanghai, China), and all patients were informed and signed informed consent. Clinical data of patients were collected for further analysis.

\section{Inclusion and exclusion criteria}

Inclusion criteria. Patients $>18$ years, and course of the disease longer that 6 months; patients who were not treated with anti-tumor drugs; patients who received no radiotherapy or chemotherapy.

Exclusion criteria. Patients with digestive disease; patients with blood relationship with other patients; patients with cirrhosis or autoimmune disease; patients with serious infection; patients who received blood transfusion recently.

\section{Detection method}

Reverse transcription-quantitative PCR (RT-qPCR). Tissues were ground in liquid nitrogen and total RNA was extracted using TRIzol reagent (Shanghai Pufei Biotechnology, Co., Ltd., Shanghai, China). RNA quality was tested by an ultraviolet spectrophotometer (Hitachi, Tokyo, Japan), and only RNA samples with a 260/280 ratio between 1.8-2.2 were used in reverse transcription to synthesize cDNA using a reverse transcription kit (Applied Biosystems; Thermo Fisher Scientific, Inc., Waltham, MA, USA). PCR reaction system was prepared using a PCR kit (Applied Biosystems; Thermo Fisher Scientific, Inc.): $10 \mu 1$ of TaqMan $2 x$ Universal Master Mix II, $2 \mu \mathrm{l}$ of each of the upstream and downstream primers, $2 \mu 1$ of cDNA template and $4 \mu 1$ of water. PCR reaction conditions: $95^{\circ} \mathrm{C}$ for $5 \mathrm{~min}$, followed by 40 cycles of $95^{\circ} \mathrm{C}$ for $15 \mathrm{sec}, 55^{\circ} \mathrm{C}$ for $35 \mathrm{sec}$ and $72^{\circ} \mathrm{C}$ for $20 \mathrm{sec}$. Each experiment was performed 3 times with GAPDH as endogenous control. Sequences of primers used in PCR reactions are listed in Table I.

Western blotting. Lung tissues were mixed with protein lysate containing protease inhibitor and ground on ice. Collected lavage fluid was centrifuged at 2,500 x g using a cryogenic centrifuge for $5 \mathrm{~min}$ at $4^{\circ} \mathrm{C}$ to remove the supernatant. Centrifugation was performed again to remove the supernatant. Then protein lysate containing protease inhibitor was added and incubated on ice. BCA kit (Thermo Fisher Scientific, Inc.) was used to measure protein concentration. After 10\% SDS-PAGE gel electrophoresis (80-120 V) for 100 min, gel transfer to a PVDF membrane was performed.
Table II. Comparison of clinical data among groups.

\begin{tabular}{|c|c|c|c|c|c|c|}
\hline Groups & $\mathrm{n}$ & $\begin{array}{c}\mathrm{LC} \\
\text { patients } \\
(\mathrm{n}=108)\end{array}$ & $\begin{array}{c}\text { IPF } \\
\text { patients } \\
(n=88)\end{array}$ & $\begin{array}{l}\text { Normal } \\
\text { controls } \\
(n=100)\end{array}$ & F-value & P-value \\
\hline Sex & & & & & 0.060 & 0.971 \\
\hline Male & 203 & 75 & 60 & 68 & & \\
\hline Female & 93 & 33 & 28 & 32 & & \\
\hline Age & & & & & 0.498 & 0.780 \\
\hline$>60$ & 174 & 65 & 49 & 60 & & \\
\hline$\leq 60$ & 122 & 43 & 39 & 40 & & \\
\hline Smoking history & & & & & 1.356 & 0.508 \\
\hline Yes & 205 & 78 & 62 & 65 & & \\
\hline No & 91 & 30 & 26 & 35 & & \\
\hline Alcoholism & & & & & 0.858 & 0.651 \\
\hline Yes & 49 & 20 & 12 & 17 & & \\
\hline No & 247 & 88 & 76 & 83 & & \\
\hline Exercise habits & & & & & 0.612 & 0.736 \\
\hline Yes & 36 & 15 & 9 & 12 & & \\
\hline No & 260 & 93 & 79 & 88 & & \\
\hline $\begin{array}{l}\text { Place of } \\
\text { residence }\end{array}$ & & & & & 0.511 & 0.775 \\
\hline Urban area & 267 & 99 & 78 & 90 & & \\
\hline Rural area & 29 & 9 & 10 & 10 & & \\
\hline Marital status & & & & & 0.166 & 0.920 \\
\hline Married & 273 & 99 & 82 & 92 & & \\
\hline Unmarried & 23 & 9 & 6 & 8 & & \\
\hline
\end{tabular}

LC, lung cancer; IPF, idiopathic pulmonary fibrosis.

The membranes were blocked with $5 \%$ skimmed milk for $1.5 \mathrm{~h}$ at room temperature. After washing with TBST, the membranes were incubated with primary antibodies $(1: 1,000$; SAB Biotherapeutics, Inc., Sioux Falls, SD, USA) overnight at $4^{\circ} \mathrm{C}$. After washing with TBST, the membranes were further incubated with secondary antibody $(1: 2,000)$ at room temperature for $1 \mathrm{~h}$. Finally, TBST (ProteinTech Group, Inc., Chicago, IL, USA) was added to develop signals. The relative expression of each protein was normalized to $\beta$-actin. Primary rabbit polyclonal FGF2 antibody (dilution: 1/1,000; cat. no. ab8880), rabbit polyclonal FGFR2 antibody (dilution: $1 / 1,000$; cat. no. ab10648), rabbit polyclonal $\beta$-actin antibody (dilution: 1/1,000; cat. no. ab8227) and secondary goat anti-rabbit (HRP) IgG antibody (dilution: 1/2,000; cat. no. ab6721) were all purchased from Abcam (Cambridge, MA, USA). 
Table III. Expression of FGF2 and FGFR2 in tissues of patients with LC and lavage fluid of patients with IPF and normal controls.

\begin{tabular}{lcccc}
\hline & \multicolumn{2}{c}{ LC patients } & & \\
\cline { 2 - 4 } Groups & $\begin{array}{l}\text { Cancer } \\
\text { tissues }\end{array}$ & $\begin{array}{c}\text { Adjacent healthy } \\
\text { tissues }\end{array}$ & t & P-value \\
\hline FGF2 mRNA & $0.984 \pm 0.134$ & $0.274 \pm 0.064$ & 49.687 & 0.001 \\
FGFR2 mRNA & $1.115 \pm 0.184$ & $0.405 \pm 0.861$ & & \\
\hline
\end{tabular}

LC, lung cancer; IPF, idiopathic pulmonary fibrosis.
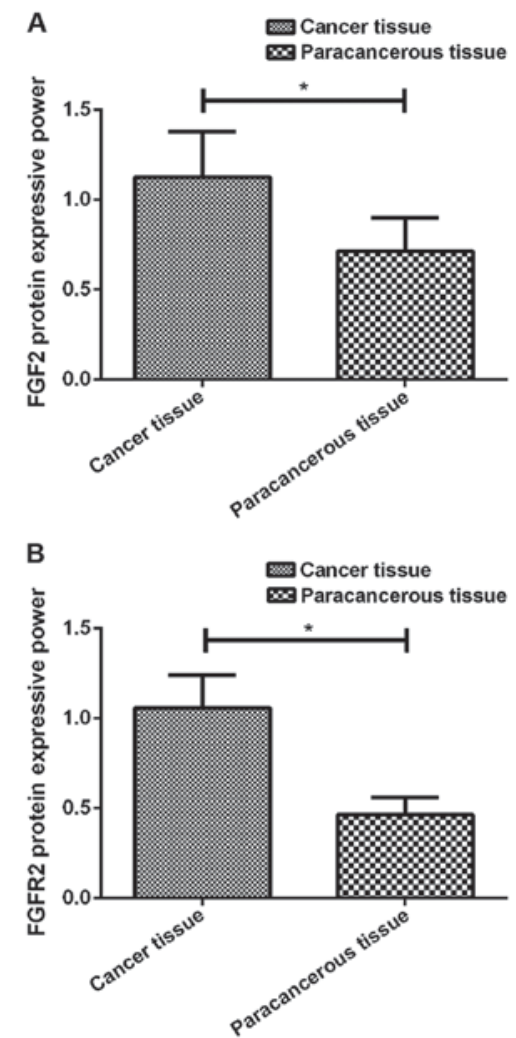

Figure 1. (A) Expression of FGF2 protein in cancer tissue of LC patients. Western blotting results showed that the expression level of FGF2 protein in cancer tissues of LC patients was significantly higher than that in the adjacent tissues ( $\left.{ }^{*} \mathrm{P}<0.05\right)$. (B) Expression of FGFR2 protein in cancer tissue of $\mathrm{LC}$ patients. Western blotting results showed that the expression level of FGFR2 protein in cancer tissues of LC patients was significantly higher than that in the adjacent tissues $\left({ }^{*} \mathrm{P}<0.05\right)$. LC, lung cancer.

Statistical analysis. SPSS 20.0 software package (IBM SPSS, Armonk, NY, USA) was used to process the collected data. Measured data were expressed as mean \pm standard deviation and compared by t-test. Count data were expressed as $\%$ and compared by Chi-square test. Comparisons among multiple groups were performed using one-way ANOVA followed by post hoc test (Least Significant Difference). $\mathrm{P}<0.05$ was considered to indicate a statistically significant difference.

\section{Results}

Comparison of clinical data among groups. No significant differences in sex, age, IBM, smoking history, alcoholism,
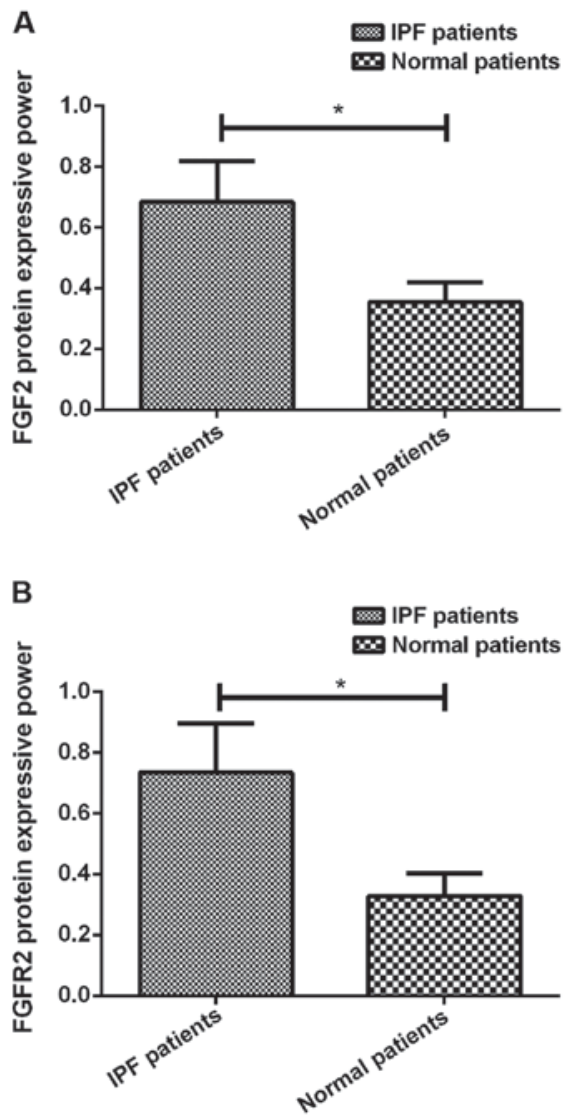

Figure 2. (A) Expression of FGF2 protein in lavage fluid of IPF patients. Western blotting results showed that the expression level of FGF2 protein in lavage fluid of IPF patients was significantly higher than that in the normal controls ("P<0.05). (B) Expression of FGFR2 protein in lavage fluid of IPF patients. Western blotting results showed that the expression level of FGFR2 protein in lavage fluid of IPF patients was significantly higher than that in the normal controls ( $\mathrm{P}<0.05)$. IPF, idiopathic pulmonary fibrosis.

exercise habits, place of residence, and marital status were found among groups $(\mathrm{P}>0.05)$ (Table II).

Relative expression levels of FGF2 and FGFR2 in each group. RT-qPCR and western blotting results showed that $F G F 2$ mRNA and protein was highly expressed in cancer tissues of LC patients, and the expression levels were significantly higher than that in the adjacent tissues $(\mathrm{P}<0.05)$. In addition, FGFR2 mRNA and protein was highly expressed in cancer tissues of LC patients, and the expression levels were significantly higher than that in the adjacent tissues $(\mathrm{P}<0.05)$. Besides that, the expression levels of FGF2 and FGFR2 proteins were also significantly higher in IPF patients than in the normal patients $(\mathrm{P}<0.05)$ (Table III; Figs. 1 and 2).

Correlation between expression of FGF2 and FGFR2 and clinicopathological data of LC patients. Correlation analysis between the expression of FGF2 and FGFR2 mRNA in cancer tissues of LC patients and patients' clinicopathological data showed that expression of FGF2 and FGFR2 in LC lung tissues was not significantly correlated with age, sex and smoking history $(\mathrm{P}>0.05)$, but was significantly correlated with lymph node metastasis, tumor differentiation, and TNM stage $(\mathrm{P}<0.05)$ (Table IV). 
Table IV. Correlation between expression of FGF2 and FGFR2 and clinicopathological data of LC patients.

\begin{tabular}{|c|c|c|c|c|c|c|c|}
\hline Clinicopathological data & $\mathrm{n}=108$ & FGF2 mRNA & $\mathrm{t} / \mathrm{F}$ & P-value & FGFR2 mRNA & $\mathrm{t} / \mathrm{F}$ & $\mathrm{P}$-value \\
\hline Age & & & 1.259 & 0.211 & & 1.211 & 0.229 \\
\hline$\geq 60$ & 65 & $0.984 \pm 0.131$ & & & $1.025 \pm 0.158$ & & \\
\hline$<60$ & 43 & $0.953 \pm 0.116$ & & & $1.063 \pm 0.162$ & & \\
\hline Sex & & & 0.179 & 0.856 & & 0.328 & 0.744 \\
\hline Male & 75 & $0.973 \pm 0.138$ & & & $1.084 \pm 0.162$ & & \\
\hline Female & 33 & $0.968 \pm 0.124$ & & & $1.073 \pm 0.158$ & & \\
\hline Smoking history & & & 0.708 & 0.480 & & 0.269 & 0.788 \\
\hline Yes & 78 & $0.975 \pm 0.132$ & & & $1.101 \pm 0.158$ & & \\
\hline No & 30 & $0.955 \pm 0.130$ & & & $1.092 \pm 0.149$ & & \\
\hline Lymph node metastasis & & & 3.783 & 0.001 & & 2.203 & 0.030 \\
\hline Yes & 97 & $1.135 \pm 0.164$ & & & $1.154 \pm 0.164$ & & \\
\hline No & 11 & $0.942 \pm 0.120$ & & & $1.041 \pm 0.132$ & & \\
\hline Differentiation & & & 6.684 & 0.002 & & 3.257 & 0.042 \\
\hline Low & 18 & $1.105 \pm 0.142$ & & & $1.112 \pm 0.178$ & & \\
\hline Moderate & 55 & $0.988 \pm 0.137$ & & & $1.035 \pm 0.163$ & & \\
\hline High & 35 & $0.965 \pm 0.133$ & & & $0.994 \pm 0.143$ & & \\
\hline TNM stage & & & 13.958 & 0.001 & & 4.682 & 0.011 \\
\hline I & 16 & $0.958 \pm 0.122$ & & & $0.998 \pm 0.149$ & & \\
\hline II & 45 & $0.994 \pm 0.143$ & & & $1.054 \pm 0.158$ & & \\
\hline III+IV & 47 & $1.132 \pm 0.155$ & & & $1.132 \pm 0.183$ & & \\
\hline
\end{tabular}

LC, lung cancer.

\section{Discussion}

LC as the most common type of malignancy in clinical practice is also one of the leading causes of cancer-related deaths in both developed and developing countries. Studies have shown that the incidence of LC is increasing every year, and the incidence rate in urban areas is the highest (9). Surgical resection is the most common treatment for LC patients, but is not acceptable for most patients. In clinical practice, chemotherapy and radiotherapy are mostly used. However, patients with long-term radiotherapy and chemotherapy will develop severe adverse reactions. IPF is a fibrosis-specific lesion, and the cause of IPF is unknown. The occurrence of IPF is related to age, sex, working environment, and smoking history (10). Hutchinson (11) retrospectively analyzed the prevalence of IPF in 21 countries, and it was found that the prevalence of IPF in the world is on the rise. With the growth of the aging population and aggregated air pollution, the incidence of IPF has been further increased. Studies have shown that the occurrence of IPF and LC share the same genetic mutations and abnormal activation of signal pathways (12), suggesting a potential link between IPF and LC.

FGFR signaling pathway is composed of FGFs and FGFRs, which were expressed in all tissues of the human body and participate in a variety of physiological processes (13). FGFs circulate through a variety of secretory pathways (autocrine, paracrine, and endocrine). FGFs bind to heparin sulfate proteoglycans to protect ligands and assist FGFRs in the activation of downstream signaling molecules (14). FGFR2 receptor is a tyrosine kinase, and studies have shown that FGFR2 is closely related to tumor angiogenesis, tumor metastasis, cancer prognosis, and plays an important role in target gene therapy (15).

In this study, the expression of FGF2 and FGFR2 in LC patients and IPF patients was detected at mRNA and protein levels. We found that FGF2 and FGFR2 expression was significantly upregulated in cancer tissues compared to the adjacent tissues in LC patients. Studies have shown that (16) FGF2 is highly expressed in various cancer tissues, Siegfried et al (17) found that FGF2 is also highly expressed in patients with non-small cell LC, which is consistent with the findings in our study. Correlation analysis between the expression of FGF2 and FGFR2 in cancer tissues of LC patients and patients' clinicopathological data showed that expression of FGF2 and FGFR2 in LC lung tissues was not significantly correlated with age, sex, histological types and smoking history, but was significantly positively correlated with lymph node metastasis and TNM stage $(\mathrm{P}<0.05)$. After the binding of FGFs to FGFRs, their receptors will dimerize and activate downstream pathways to promote cell proliferation, invasion, migration, and epithelialmesenchymal transition (18). Therefore, we speculated that the high expression levels of FGFs and FGFRs were associated with tumor invasion. In this study, the expression levels of FGF2 and FGFR2 proteins in lavage fluid were also found to be significantly higher in IPF patients than in the normal patients.

Studies have shown that $(19,20)$ upregulation of FGF2 expression plays an important role in the development of chronic silica dust, silicosis and IPF, and FGF2 is directly involved in the development of lung damage after bleomycin-induced lung injury in mice. In addition, studies on bluntin-induced lung injury in mice showed that FGF2 is directly involved in cell 
proliferation and fibrosis formation in mice after lung injury. Therefore, we hypothesized that neovascularization in patients with IPF may be mediated by the FGF2/FGFR2 pathway.

However, our study also has some limitations. The expression of FGF2 and FGFR2 in IPF patients was not detected at the mRNA level, and the downstream pathways were not investigated. All patients were from the local region, and regional differences were not excluded. We will try to detect FGF2 and FGFR2 mRNA in the peripheral blood of patients with IPF, increase the number of test items, and increase the sample size in our future studies to further validate our conclusions.

In conclusion, FGF2 and FGFR2 proteins were highly expressed in cancer tissues of LC patients and lavage fluid of patients with IPF. The expression of FGF2 mRNA and FGFR2 mRNA was correlated with lymph node metastasis and TNM stage. The high expression levels of FGF2 mRNA and FGFR2 mRNA were associated with tumor metastasis and poor prognosis of LC patients.

\section{Acknowledgements}

Not applicable.

\section{Funding}

The study was supported by the Foundation project of Shanghai Municipal Health and Family Planning Commission 2016 (20164Y0241).

\section{Availability of data and materials}

The datasets used and/or analyzed during the present study are available from the corresponding author on reasonable request.

\section{Authors' contributions}

LL drafted the manuscript. LL and SZ were mainly devoted to collecting and interpreting the basic data of patients. LW and ZW helped with RT-qPCR. WM, FL and YQ were responsible for statistical analysis. All authors read and approved the final study.

\section{Ethics approval and consent to participate}

The study was approved by the Ethics Committee of Shanghai Pulmonary Hospital (Shanghai, China). Signed informed consents were obtained from the patients or the guardians.

\section{Patient consent for publication}

Not applicable.

\section{Competing interests}

The authors declare that they have no competing interests.

\section{References}

1. Zhang Y, Wei X and Pan T: Simultaneous surgical treatment of non-small cell lung cancer and off-pump coronary artery bypass grafting. Zhongguo Fei Ai Za Zhi 12: 332-336, 2009 (In Chinese).
2. Sheffield BS, Fulton R, Kalloger SE, Milne K, Geller G, Jones M, Jacquemont C, Zachara S, Zhao E, Pleasance E, et al: Investigation of PD-L1 biomarker testing methods for PD-1 axis inhibition in non-squamous non-small cell lung cancer. J Histochem Cytochem 64: 587-600, 2016.

3. Sorber L, Zwaenepoel K, Deschoolmeester V, Van Schil PE, Van Meerbeeck J, Lardon F, Rolfo C and Pauwels P: Circulating cell-free nucleic acids and platelets as a liquid biopsy in the provision of personalized therapy for lung cancer patients. Lung Cancer 107: 100-107, 2017.

4. Zhang X, Liu Y, Shao H and Zheng X: Obesity paradox in lung cancer prognosis: Evolving biological insights and clinical implications. J Thorac Oncol 12: 1478-1488, 2017.

5. Richeldi L, Collard HR and Jones MG: Idiopathic pulmonary fibrosis. Lancet 389: 1941-1952, 2017.

6. Raghu G, Brown KK, Collard HR, Cottin V, Gibson KF Kaner RJ, Lederer DJ, Martinez FJ, Noble PW, Song JW, et al: Efficacy of simtuzumab versus placebo in patients with idiopathic pulmonary fibrosis: A randomised, double-blind, controlled, phase 2 trial. Lancet Respir Med 5: 22-32, 2017.

7. Raghu G, Wells AU, Nicholson AG, Richeldi L, Flaherty KR, Le Maulf F, Stowasser S, Schlenker-Herceg R and Hansell DM: Effect of nintedanib in subgroups of idiopathic pulmonary fibrosis by diagnostic criteria. Am J Respir Crit Care Med 195: 78-85, 2017.

8. Morrissey C, Corey E, Brown L, Coleman I, Nguyen H, Schweizer $M$ and Nelson P: Targeting the FGFR pathway in androgen receptor negative castration resistant prostate cancer. Cancer Res 77: Abst 2076, 2017. doi:10.1158/1538-7445. AM2017-2076

9. Riihimäki M, Hemminki A, Fallah M, Thomsen H, Sundquist K, Sundquist $\mathrm{J}$ and Hemminki $\mathrm{K}$ : Metastatic sites and survival in lung cancer. Lung Cancer 86: 78-84, 2014.

10. Martinez FJ, de Andrade JA, Anstrom KJ, King TE Jr and Raghu G; Idiopathic Pulmonary Fibrosis Clinical Research Network: Randomized trial of acetylcysteine in idiopathic pulmonary fibrosis. N Engl J Med 370: 2093-2101, 2014.

11. Hutchinson J: Idiopathic pulmonary fibrosis: Another step in understanding the burden of this disease. Eur Respir J 48: 26-28, 2016.

12. Chen DL, Wang ZQ, Zeng ZL, Wu WJ, Zhang DS, Luo HY, Wang F, Qiu MZ, Wang DS, Ren C, et al: Identification of microRNA-214 as a negative regulator of colorectal cancer liver metastasis by way of regulation of fibroblast growth factor receptor 1 expression. Hepatology 60: 598-609, 2014.

13. Katoh M and Nakagama H: FGF receptors: Cancer biology and therapeutics. Med Res Rev 34: 280-300, 2014.

14. Goyal L, Saha SK, Liu LY, Siravegna G, Leshchiner I, Ahronian LG, Lennerz JK, Vu P, Deshpande V, Kambadakone A, et al: Polyclonal secondary FGFR2 mutations drive acquired resistance to FGFR inhibition in patients with FGFR2 fusion-positive cholangiocarcinoma. Cancer Discov 7: 252-263, 2017.

15. Li D, Zhang H, Ma L, Han Y, Xu M, Wang Z, Jiang H, Zhang W, Wang L and Pan Y: Associations between microRNA binding site SNPs in FGFs and FGFRs and the risk of non-syndromic orofacial cleft. Sci Rep 6: 31054, 2016.

16. Soulitzis N, Karyotis I, Delakas D and Spandidos DA: Expression analysis of peptide growth factors VEGF, FGF2, TGFB1, EGF and IGF1 in prostate cancer and benign prostatic hyperplasia. Int J Oncol 29: 305-314, 2006.

17. Siegfried JM, Farooqui M, Rothenberger NJ, Dacic S and Stabile LP: Interaction between the estrogen receptor and fibroblast growth factor receptor pathways in non-small cell lung cancer. Oncotarget 8: 24063-24076, 2017.

18. Babina IS and Turner NC: Advances and challenges in targeting FGFR signalling in cancer. Nat Rev Cancer 17: 318-332, 2017.

19. Mori Y, Nakamura S, Kishimoto S, Kawakami M, Suzuki S, Matsui $\mathrm{T}$ and Ishihara M: Preparation and characterization of low-molecular-weight heparin/protamine nanoparticles (LMW-H/P NPs) as FGF-2 carrier. Int J Nanomed 5: 147-155, 2010.

20. Hasday JD, Scheraga RG, Thompson C, Tulapurkar M, Cowan MJ, Sun JF, Cai RM, Logun C, Todd NW, Shelhamer J, et al: Heat-Shock accelerates human lung epithelial wound healing by activating expression of fibroblast growth factor (FGF)-1: Implications for idiopathic pulmonary fibrosis (IPF). Am J Respir Crit Care Med 193: A1461, 2016. 